\title{
Implementation of 3-Phase Induction Motor through Indirect Vector Control Using PID Controller with Fuzzy Logic Techniques
}

\author{
Amit Kumar Meshram¹, Amit Goswami \\ ${ }^{1}$ M. Tech Scholar, Electronics \& Electrical Engineering, DIMAT, Raipur, Chhattisgarh, India \\ ${ }^{2}$ Assistant Professor, Electronics \& Electrical Engineering, DIMAT, Raipur, Chhattisgarh, India
}

\begin{abstract}
This Project Thesis titled "Implementation of 3-Phase Induction Motor through Indirect Vector Control Using PID Controller with Fuzzy Logic Techniques" This paper proposes the implementation of 3-phase induction motor through indirect vector controlled induction motor (IM) drive involves decoupling of the stator current into torque and flux producing components of an induction motor. This paper involves PID Controller of driver and motors with fuzzy logic techniques.
\end{abstract}

Keywords: Indirect Vector Control (IVC), 3-Phase Induction Motors, PID Controller

\section{Introduction}

The electrical machine that converts electrical energy into mechanical energy, and vice versa, is the workhorse in a drive system. Induction motors have been used for over a century because of their simplicity, ruggedness and efficiency [2]. The

asynchronous or induction motor is the most widely used electrical drive. Separately excited dc drives are simpler in control because independent control of flux and torque can be brought about [9]. In contrast, induction motors involve a coordinated control of stator current magnitude and the phase, making it a complex control. The stator flux linkages can be resolved along any frame of reference. This requires the position of the flux linkages at every instant. Then the control of the ac machine is very similar to that of separately excited dc motor. Since this control involves field coordinates it is also called field oriented control (Vector Control) [4]. Depending on the method of measurement, the vector control is divided into two subcategories: direct and indirect vector control. In direct vector control, the flux measurement is done by using the flux sensing coils or the Hall devices. The most common method is indirect vector control. In this method, the flux angle is not measured directly, but is estimated from the equivalent circuit model and from measurements of the rotor speed, the stator current and the voltage [1]. The Main purpose of two level inverter topologies is to provide a three phase voltage source, where the amplitude, phase, and frequency of the voltages should always be controllable [9].

\section{Induction Motor Modelling}

The steady-state model and equivalent circuit are useful for studying the performance of machine in steady state. This implies that all electrical transients are neglected during load changes and stator frequency variations. The dynamic model of IM is derived by using a two-phase motor in direct and quadrature axes, where $d s^{-} q s$ correspond to stator direct and quadrature axes and $d r-q r$ correspond to rotor direct and quadrature axes [3]. The dynamic analysis and description of revolving field machines is supported by well established theories. An Induction Motor of uniform air gap, with sinusoidal distribution of $\mathrm{mmf}$ is considered. The saturation effect and parameter changes are neglected.

\section{Indirect Vector Control with PID}

In the indirect vector control the unit vectors are generated in feed forward manner, indirect vector control is very popular in industrial application. The figure shown below,

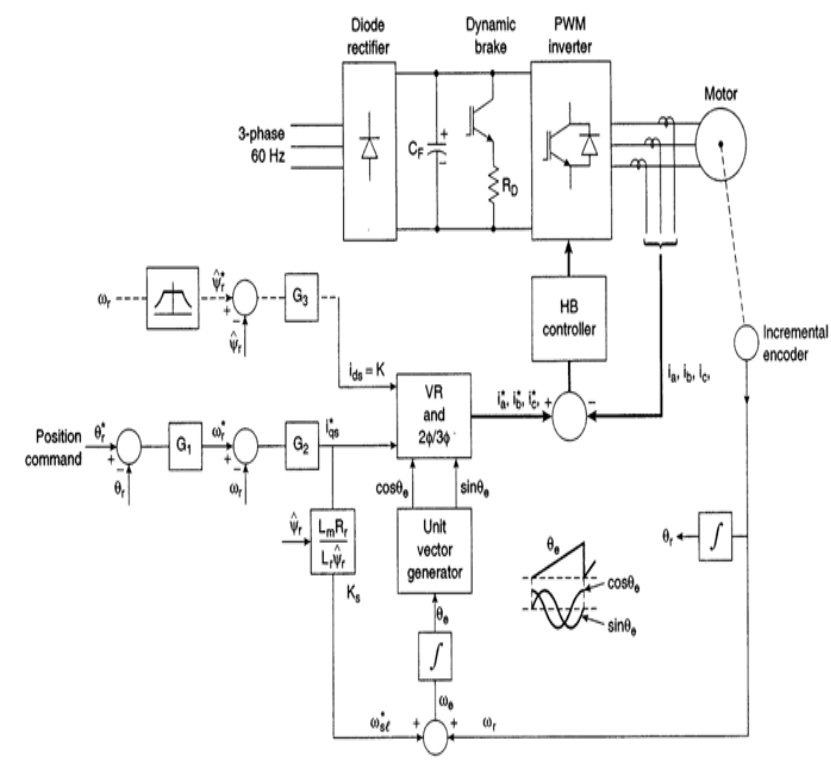

Figure 1: Block Diagram of indirect vector control

PID controller: PID controller has all the necessary dynamics: fast reaction on change of the controller input (D mode), increase in control signal to lead error towards zero (I mode) and suitable action inside control error area to eliminate oscillations ( $\mathrm{P}$ mode). Derivative mode improves stability of the system and enables increase in gain $\mathrm{K}$ and decrease in integral time constant $\mathrm{Ti}$, which increases speed of the controller response. PID controller is used when dealing with higher order capacitive processes (processes with more than one energy storage) when their dynamic is 


\section{International Journal of Science and Research (IJSR) \\ ISSN (Online): 2319-7064}

Index Copernicus Value (2013): 6.14 | Impact Factor (2015): 6.391

not similar to the dynamics of an integrator (like in many thermal processes). PID controller is often used in industry, but also in the control of mobile objects (course and trajectory following included) when stability and precise reference following are required. Conventional autopilot is for the most part PID type controllers.

Fuzzy-Controller: PID controller are the occurrence of overshoot while starting, undershoot while load application and overshoot again while load removal. In the fuzzification block, the inputs and outputs crisp variables are converted into fuzzy variables 'e', 'de' and 'du' using the triangular membership function shown in figure 2 .

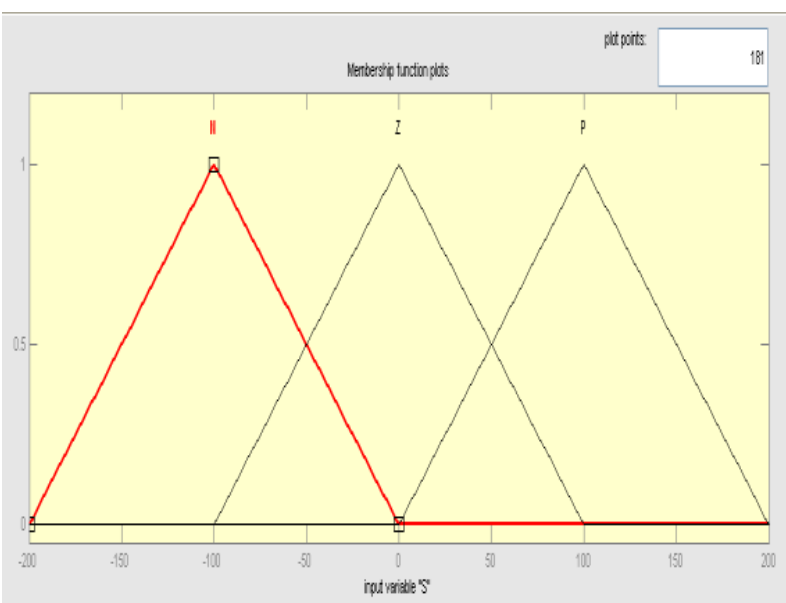

Figure 2: Shows membership function for control variables

The fuzzification block produces the fuzzy variables ' $\mathrm{e}$ ' and 'de' using their crisp counterpart. These fuzzy variables are then processed by an inference mechanism based on a set of control rules contained in $(3 * 3)$. The fuzzy rules are expressed using the IF-THEN form. The crisp output of the FLC is obtained by using MAX-MIN inference algorithm and the center of gravity de-fuzzification approach. The performance of the fuzzy controller depends on the membership functions, their distribution and the fuzzy rules that describe the control algorithm. There is no formal method to determine the parameters of the controller accurately. In this controller, FL is used for precompensation of reference speed, which means that the reference speed signal $\left(\mathrm{w}^{*}\right)$ is changed in advance in accordance with the rotor speed, so that a new reference speed signal ( $\mathrm{w} 1^{*}$ ) is obtained and the main control action is performed by PI controller. The speed error $\left(\mathrm{e}(\mathrm{n})^{*}\right)$ and the change in speed error are the inputs to the FL, the output of the FL controller is added to the reference speed to generate a pre-compensated reference speed, which is to be used as a reference speed signal by the PI controller. In same the fuzzification block, the inputs and outputs crisp variables are converted into fuzzy variables 'e', 'de' and 'du' using the triangular membership function shown in figure 3 .

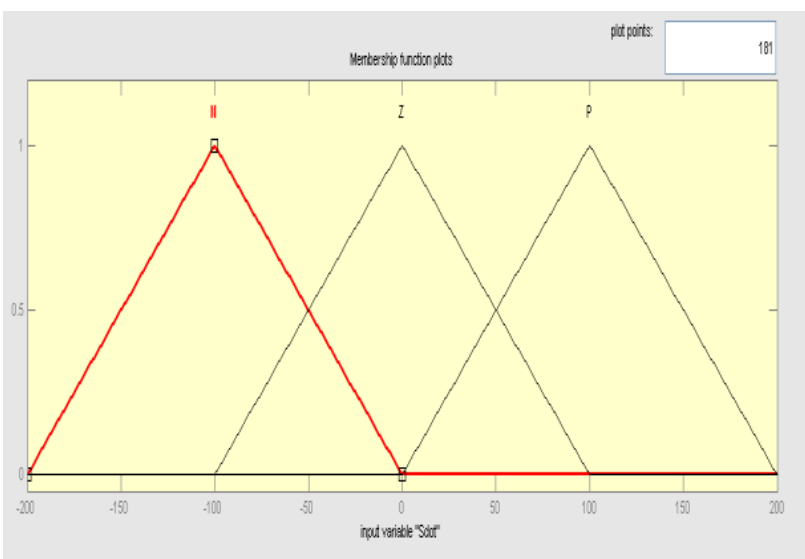

Figure 3: Shows membership function for control variables

\section{Simulation Result}

The complete model and fuzzification of Induction motors through PID Controller, the performance simulation result shown below.

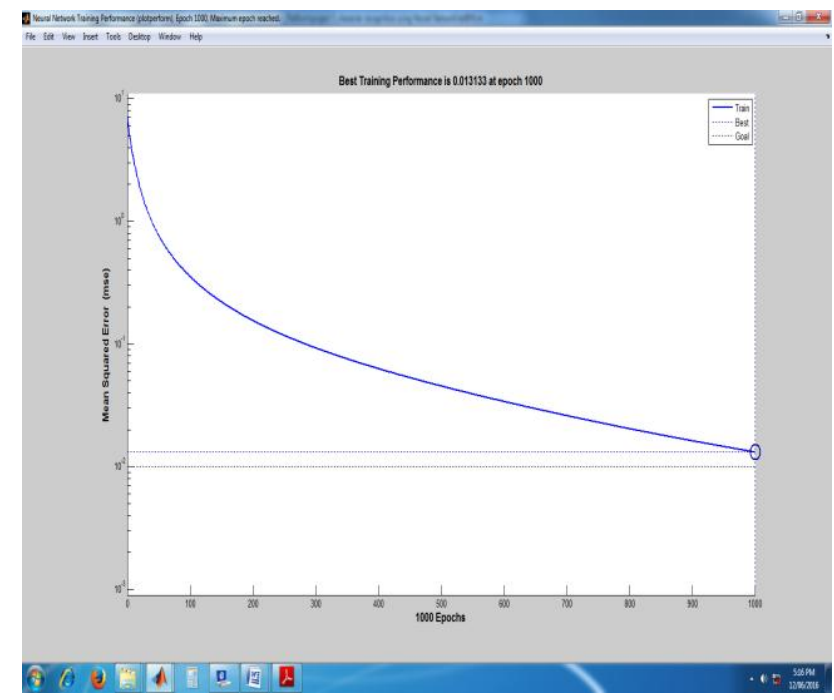

Figure 4: Simulation Result (Performance of IM)

\section{Conclusion}

In this work, indirect vector controlled 3-phase induction motor driver and motors is implemented. Estimating the rotor flux and the magnetizing current in a synchronously rotating reference frame. This paper has basic idea about PID controller with fuzzy logic of 3-phase induction motor is implemented.

\section{References}

[1] F.Blaschke, "The principle of field orientation as applied to the new trans vector closed-loop control system for rotating field Machines", Siemens Review, vol.34, pp.217-220, May 1972.

[2] Rajesh Kumar R.A. Gupta, S.V. Bhangale, "Indirect Vector Controlled Induction Motor Drive with Fuzzy Logic Based Intelligent Controller", ICTES 2007, pp.368- 373 . 


\section{International Journal of Science and Research (IJSR) \\ ISSN (Online): 2319-7064}

Index Copernicus Value (2013): 6.14 | Impact Factor (2015): 6.391

[3] Burak Ozpineci, L.M.Tolbertr, Simulink Implementation of Induction Machine Model-A modular approach, IEEE rans. 2003.

[4] S. A. Shirsavar, M. D. McCulloch and C. G. Guy, "Speed Sensor lessVector Control of Induction Motor with Parameter Estimation, "IEEE Conf. On Industrial Applications, vol.1, pp. 262-269, 1996.

[5] A. Schonug and H. Stemmler, "Static frequency changers with subharmonic control in conjunction with reversible variable speed AC drives,"Brown Boveri Rev., pp. 555-577, Sept. 1964.

[6] B. Wang and J. Cathey, "DSP-controlled, space-vector PWM, current ource converter for STATCOM application," Electric Power Systems Research, vol. 67, no.2, pp. 123-131, Nov. 2003.

[7] J. Holtz. 1992. Pulse width modulation-A Survey. IEEE Trans. Ind. Electron. 39(5): 410-420.

[8] J. Holtz. 1994. Pulse width modulation for electronic power conversion. Proc. IEEE. 82(8): 1194-1214.

[9] H. W. vander Broek, H. C. Skudelny, and G. V. Stanke, "Analysis and realization of PWM based on voltage space vectors," IEEE Trans. Ind. Applicat., vol. 24, no. 1, pp. 142-150, 1988.

[10] V. Blasko, "A hybrid PWM strategy combining modified space vector and triangle comparison methods," in IEEE PESC Conf. Rec., 1996, pp.18721878.

[11] Bose B.K, Power Electronics and Motor Drives, Academic Press,Imprint of Elsevier, 2006.

[12] R. Krishnan, Electrical Motor Drives, Modeling, Analysis and Control, Prentice Hall India Pvt. Ltd.

Volume 5 Issue 6, June 2016

www.ijsr.net

Licensed Under Creative Commons Attribution CC BY 